\title{
La competencia lingüística en español (L1) en pacientes con trastorno del espectro autista: un estudio de caso
}

\author{
Lisa Gozzi
}

Universidad de Alcalá

RESUMEN: El autismo es un trastorno del desarrollo que afecta a la comunicación y a las interacciones sociales. Se caracteriza por la presencia de patrones conductuales rígidos y estereotipados, una gama limitada de intereses e importantes déficits lingüísticos, que varían según la gravedad de cada paciente. La primera parte del presente trabajo analiza qué es el autismo y cuáles son sus síntomas, poniendo énfasis sobre las deficiencias lingüísticas y comunicativas. Asimismo, se consideran el diagnóstico y las evaluaciones necesarias para detectar la presencia de dicho trastorno. La segunda parte del trabajo consiste en el análisis de un estudio de caso, un niño con autismo cuya lengua materna es el español, para determinar y analizar sus habilidades lingüísticas y comparar los resultados con los conocimientos generales sobre el trastorno.

PALABRAS CLAVE: autismo, síntomas, lenguaje, comunicación, estudio de caso, educación.

\section{Linguistic competence in Spanish (L1) in patients with autism spectrum disorder: a case study}

ABSTRACT: Autism is a developmental disorder that affects communication and social interactions. It is characterised by the presence of strict stereotyped behavioural patterns, a restricted range of interests and important language impairments, which vary depending on the gravity of each patient. The first part of this article analyses what autism is and which its symptoms are, emphasising linguistic and communicative deficits. It also considers the process of diagnosis and the necessary evaluations to detect such a disorder. The second part of the article consists in the analysis of a case study of a child with autism, whose mother tongue is Spanish. It it his language abilities will be determined and analysed, and the results obtained in the study compared with the existing general knowledge about the disorder.

KEYWORDS: autism, symptoms, language, communication, case study, education. 


\section{Introducción}

El lenguaje es el medio principal, aunque no el único, que los seres humanos utilizan para comunicarse entre sí, para transmitir un mensaje, una información, de un hablante (emisor) a otro (receptor) (Graffi y Scalise 2013). Sin embargo, algo que parece tan natural como la comunicación y el uso correcto del lenguaje representa un desafío importante para algunas personas que sufren trastornos que afectan significativamente a estas capacidades. Este es el caso de las personas con trastornos del espectro autista (TEA). El autismo es un "trastorno del desarrollo que afecta a la comunicación y a la interacción social" y está "caracterizado por patrones de comportamiento restringidos, repetitivos y estereotipados" (DLE 2020). La alteración de la comunicación y del lenguaje es un síntoma característico de esta patología y constituye un factor fundamental para el diagnóstico de TEA, según las indicaciones especificadas en el DSM-V (Biondi y American Psychiatric Association 2014).

Este trabajo se plantea analizar el lenguaje y la comunicación en los casos de TEA, no solo desde un punto de vista teórico, sino también a través de la realización de un estudio de caso. En concreto, los objetivos de este trabajo son:

1. Examinar qué es el autismo y cuáles son los síntomas asociados normalmente a esta patología.

2. Analizar el desarrollo de la competencia lingüística en español de un estudio de caso con un doble propósito:

a) Comprobar qué comportamientos típicos del autismo presenta.

b) Demostrar que cada caso de autismo es único y particular.

Para cumplir el primer objetivo, ha sido necesario consultar la bibliografía relacionada con el campo de estudio. Además, esta consulta ha permitido obtener información para realizar el estudio de caso y analizar los resultados. La información obtenida en esta fase de la investigación se resume en el Marco Teórico. Posteriormente, para cumplir los demás objetivos ha sido necesario seguir una metodología concreta. De hecho, durante la realización del estudio se siguió un procedimiento específico que permitió documentar su historial clínico y trazar un perfil de las competencias del caso. Asimismo, se realizaron unas pruebas concretas a través de las que se pudo analizar sus habilidades lingüísticas. Los detalles sobre la metodología empleada se encuentran en el apartado 3.1. Metodología de estudio. 


\section{Marco Teórico}

\subsection{Los trastornos del espectro autista}

\subsubsection{Bases biológicas y síntomas}

Los trastornos del espectro autista (TEA) son afecciones neuropsiquiátricas cuyos primeros síntomas se manifiestan ya a los tres años de edad y permanecen durante toda la vida (Álvarez-Alcántara 2007). Se conocen también como trastornos generalizados del desarrollo y se caracterizan principalmente por problemas en la interacción social, en la comunicación verbal y no verbal, y por la presencia de comportamientos inusuales o estereotipados (Roccella 2008)․․ El Manual de Diagnóstico Estadístico de Trastornos Mentales V (en inglés Diagnostic and Statistical Manual of Mental Disorders $V$, en adelante DSM-V, publicado en 2013) reúne las distintas manifestaciones de este tipo de afección (autismo, Síndrome de Asperger y trastorno generalizado del desarrollo sin especificación) bajo la definición de trastornos del espectro autista y proporciona especificadores para dar cuenta de la variabilidad en los síntomas de los trastornos: por ejemplo, se puede indicar la presencia o la ausencia de déficits intelectuales y de problemas a nivel lingüístico (Regier, Kuhl y Kupfer 2013).

El autismo clásico, cuyo síntoma principal es el aislamiento social, se manifiesta ya en las primeras semanas de vida del niño, en quien se nota una ausencia de actitudes sociales presentes en los demás niños, como la búsqueda del contacto visual o la adquisición de la sonrisa social. La normal interacción social resulta anómala: el niño evita el contacto físico con los demás, no comunica a través de gestos expresivos y manifiesta comportamientos estereotipados y ritualizados. Además, el niño autista expresa poca o ninguna emoción a través de la mirada y sus capacidades lingüísticas resultan alteradas y comprometidas (Roccella 2008).

A pesar de que el autismo se define como un trastorno conductual y no presenta una etiología específica, en los últimos años se ha intentado identificar las causas neurobiológicas que expliquen su origen. Una anomalía biológica importante que podría estar implicada en el

\footnotetext{
${ }^{1}$ Las estereotipias, o comportamientos estereotipados, son movimientos, posturas o sonidos que se emplean de forma ritualizada, repetitiva, sin objetivo específico y en los contextos más variados. En algunos casos, se consideran comportamientos extraños e inusuales porque su utilización es inadecuada al contexto de uso. Unos ejemplos de estereotipias son mirarse las manos, adoptar una postura particular o mover manos y dedos de una forma específica. En la comunicación, se consideran comportamientos estereotipados la repetición de palabras y frases o la emisión de determinados sonidos y vocalizaciones.
} 
desarrollo de los trastornos del espectro autista es una disfunción en el sistema de las neuronas espejo, descubiertas entre los años 80 y 90 del siglo pasado por un equipo de científicos de la Universidad de Parma a partir de una serie de experimentos con chimpancés. Giacomo Rizzolatti y sus colegas descubrieron que en la corteza premotora del animal había neuronas que se activaban no solo cuando el chimpancé realizaba un movimiento, como agarrar un objeto, sino también cuando veía a alguien más ejecutar la misma acción (Cacciari 2011). Estas neuronas fueron encontradas también en otros animales, incluidos los seres humanos, y hay evidencias de que en estos últimos desarrollan un papel importante en el reconocimiento, identificación e imitación de las acciones de los demás (Cornelio-Nieto 2009). Las neuronas espejo son tanto motoras como sensoriales, se supone que están en la base de la comprensión de las acciones e intenciones de los demás y que, por consiguiente, están en la base de los procesos de imitación y del aprendizaje por imitación. Se puede notar que las neuronas espejo parecen efectuar las mismas funciones que resultan alteradas en el autismo, por lo tanto, una disrupción de este circuito neuronal podría explicar en gran parte la sintomatología del autismo, esto es, la falta de habilidades sociales en el individuo (Cornelio-Nieto 2009).

Otro dato importante es que el área de la corteza cerebral de los primates donde se encuentran las neuronas espejo corresponde al área de Broca en el cerebro humano, una de las áreas donde residen las capacidades lingüísticas (Cacciari 2011). Por consiguiente, un déficit en las neuronas espejo podría explicar también las dificultades lingüísticas características de los trastornos del espectro autista.

\subsubsection{Diagnóstico}

El diagnóstico de los trastornos del espectro autista se suele realizar a través de un proceso de diagnóstico diferencial, un método deductivo que se utiliza cuando no es posible individuar una enfermedad con solo un examen clínico porque presenta síntomas similares a los de otras enfermedades. Por lo tanto, se consideran todos los trastornos que pueden causar ciertos síntomas y, a través de una serie de exámenes físicos y entrevistas, se identifica una enfermedad específica (MedlinePlus 2019).

El diagnóstico diferencial del trastorno autista, según el DSM-V, se debe plantear con otros trastornos como el Síndrome de Rett, el trastorno desintegrativo infantil, el mutismo selectivo, el trastorno expresivo y el trastorno mixto del lenguaje, el trastorno por déficit de atención e hiperactividad, el trastorno de movimientos estereotípicos, esquizofrenia y retraso mental. Sin embargo, se excluyen el trastorno desintegrativo infantil y el Síndrome de 
Asperger que estaban incluidos en la versión anterior (DSM-IV) (Biondi y American Psychiatric Association 2014).

Según el DSM-V, para diagnosticar un trastorno del espectro autista el paciente debe manifestar déficits constantes en varios contextos de la comunicación y de la interacción social, debe mostrar patrones de comportamiento e intereses restringidos y repetitivos; asimismo, los síntomas deben aparecer precozmente en el desarrollo del niño y comprometer de manera clínicamente significativa las actividades del paciente en el ámbito social, laboral u otros contextos importantes; finalmente, también es necesario que las alteraciones mencionadas no se puedan explicar por discapacidad intelectual o un retraso global del desarrollo. Además de los criterios diagnósticos que se acaban de indicar, hay una serie de especificadores que se usan para describir los síntomas del paciente en el momento del diagnóstico (Biondi y American Psychiatric Association 2014). El diagnóstico diferencial es la primera fase en el proceso de diagnóstico del autismo; posteriormente, una vez se obtenga un perfil clínico personalizado, se deberá continuar con la evaluación mediante pruebas específicas que permitan establecer el tratamiento más adecuado para el paciente.

Por lo que concierne al pronóstico de los trastornos del espectro autista, la patología avanza a medida que el niño crece y las necesidades específicas causadas por la enfermedad persisten también en la edad adulta. A lo largo del tiempo, el paciente adquiere nuevas competencias y habilidades, aunque es posible que estas sufran la influencia del trastorno y, por consiguiente, presenten rasgos típicos del autismo (Mele 2015). No es simple generalizar sobre el pronóstico del autismo, puesto que el trastorno es muy variado y afecta de manera diferente a los pacientes. Como afirma García de la Torre (2002:410),

Los factores que influyen principalmente en el pronóstico son: la gravedad de la disfunción cerebral y su deficiencia mental concomitante y las habilidades lingüísticas. Un pequeño porcentaje de niños diagnosticados como autistas llegan a tener una vida autónoma y prácticamente normal en la edad adulta. Sin embargo, suelen persistir algunas deficiencias de comunicación y un repertorio de intereses bastante restringido.

\subsection{Comunicación y lenguaje en casos de TEA}

\subsubsection{La comunicación en el autismo}

La comunicación es un proceso en el que se realiza un intercambio exitoso de información a través del uso de signos (Serra i Raventós 1984). El proceso comunicativo es algo que implica el uso no solo de una lengua, sino también de otras importantes herramientas. De hecho, como especifica Cestero Mancera (2016: 2): 
La comunicación humana es un proceso extraordinariamente complejo. Durante décadas, se ha considerado que era posible gracias a la competencia lingüística; no obstante, desde hace ya más de medio siglo, somos plenamente conscientes de que supone mucho más que conocer y utilizar un sistema lingüístico: implica no solo el uso de una lengua determinada, sino, también, la posesión y la utilización de información pragmática, social, situacional y geográfica, y de signos de los sistemas de comunicación no verbal [...].

Los síntomas del autismo, como se ha explicado anteriormente, afectan y alteran muchas de las competencias necesarias para poder empezar y mantener una conversación: de hecho, la presencia de déficits en la comunicación y en la interacción social representa una parte importante de los trastornos del espectro autista (Prizant 1983). El 25\% de los pacientes con TEA no desarrolla su propio lenguaje y no se comunica a través de otros canales como los gestos o las expresiones faciales (Roccella 2008). En efecto, las personas con trastorno del espectro autista presentan dificultades no solo en la adquisición del lenguaje, sino también en la comprensión y el uso de la comunicación no verbal (National Research Council 2001).

En relación con la comunicación en sí misma, dos de las áreas donde los autistas presentan más dificultades son la atención conjunta y el uso de los símbolos comunicativos. La falta de desarrollo de la atención conjunta representa un problema importante, ya que parece ser uno de los factores críticos que dificultan una evolución lingüística normal en los niños autistas:

Joint attention reflects difficulty coordinating attention between people and objects and is evident by deficits in orienting and attending to a social partner; shifting gaze between people and objects; sharing affect or emotional states with another person; following the gaze and point of another person; and being able to draw another persons' attention to objects or events for the purpose of sharing experiences (National Research Council 2001: 48).

Por otro lado, también el uso de símbolos convencionales como gestos o palabras con un significado específico resulta comprometido en las personas con TEA. De hecho, estos pacientes tienen un repertorio de gestos limitados cuantitativa y cualitativamente, suelen comunicarse a través de gestos primitivos y no usan gestos convencionales como saludar o asentir moviendo la cabeza (National Research Council 2001). Hay que subrayar la aparición en niños autistas de comportamientos no convencionales e incluso agresivos para compensar la carencia de otros instrumentos comunicativos. Entre estos comportamientos, se destaca la presencia de reacciones agresivas, de cólera y de actos de autolesión como medio para obtener la atención de quien está alrededor, para evitar una tarea o como forma de protesta cuando se introduce algún cambio en la rutina del niño (National Research Council 2001). 
Hay que mencionar la percepción parcial que los sujetos autistas tienen del mundo, hecho que tiene consecuencias directas en su desarrollo lingüístico. Esto puede afectar a la creación de símbolos en la mente del sujeto, y muestra de esto pueden ser ejemplos como el caso de un niño que dejó de beber porque sus padres le cambiaron su vaso verde habitual por uno rojo, lo que provocó que su hijo perdiera el concepto de beber (Noens y VanberckelaerOnnes 2004). Otra consecuencia de esta percepción limitada del mundo se refleja en la literalidad del lenguaje autista: un ejemplo de la interpretación literal de la lengua está en el caso de un niño con TEA que, jugando al tenis, antes de lanzar la pelota, la empujó contra su ojo porque su madre le había dicho keep an eye on the ball (literalmente, mantener un ojo sobre la pelota) (Noens y Vanberckelaer-Onnes 2004).

Por último, es posible también hallar algunos neologismos en el habla de los niños autistas. Un ejemplo se puede encontrar en un paciente que inventó la palabra tankshon para indicar el gel: el neologismo se debe a la asociación que el niño hizo entre la palabra gel y Shell (la compañía de gasolina holandesa), asociando sucesivamente esta última a la palabra holandesa tankstation (en español, gasolinera, estación de servicio). Estas conexiones en la mente del niño llevaron a la creación del neologismo (Noens y Vanberckelaer-Onnes 2004).

\subsubsection{El lenguaje en sujetos con TEA}

\section{Adquisición y desarrollo}

Por lo que respecta a la adquisición del lenguaje en niños autistas, es necesario especificar que existen dos formas diferentes a través de las que normalmente un niño adquiere la capacidad lingüística y su uso: la analítica y la gestáltica. Los niños que adoptan el modo analítico de adquisición del lenguaje, en las primeras etapas del desarrollo lingüístico, perciben y dividen el discurso en palabras individuales, siendo estas las primeras unidades articuladas por el sujeto en breves secuencias (O’Grady y Benítez Burraco 2010).

La otra técnica de adquisición se denomina gestáltica y consiste en la memorización y posterior emisión de fragmentos de habla completos, más o menos extensos y a menudo articulados imperfecta o incorrectamente, que el niño escucha en la comunicación de los adultos. La denominación "gestáltica" para esta forma de adquisición procede del término alemán gestalt (en español, forma), que los psicólogos utilizan para indicar patrones, esto es, estructuras que se emplean para crear el propio modelo de realidad, que el niño percibe como una unidad (O’Grady y Benítez Burraco 2010). En las primeras etapas, el lenguaje gestáltico resulta bastante inflexible, sin embargo, al avanzar el desarrollo del niño, los fragmentos de habla anteriormente aprendidos pueden ser divididos y analizados en varios componentes 
lingüísticos con el objetivo de enriquecer el propio lenguaje o pueden ser combinados en nuevos bloques más complejos, pasando así a un modelo más analítico (Prizant 1983).

Los dos modelos descritos no están completamente separados, sino que forman un continuo. Los niños no emplean exclusivamente uno de los dos sistemas a la hora de adquirir el lenguaje, sino que usan uno de forma mayoritaria, sin que implique la exclusión total del otro (O’Grady y Benítez Burraco 2010). Hay que notar que el modelo gestáltico resulta ser menos funcional en el proceso de desarrollo lingüístico y que esto provoca que, con el paso del tiempo, normalmente se evolucione hacia una forma analítica. Sin embargo, este cambio es difícil y lento. A la hora de adquirir el lenguaje, los niños autistas parecen adoptar un modelo extremadamente gestáltico, sin lograr avanzar hacia una forma más analítica debido a las limitaciones cognitivas que el trastorno implica. Solo los sujetos con un potencial cognitivo mayor dan ese paso y pueden acercarse a una orientación más analítica (Prizant 1983).

\section{Características del lenguaje en el autismo}

Las habilidades lingüísticas de los sujetos con TEA son muy variadas, van desde ausencia total de lenguaje que desemboca en una condición de mutismo, hasta un lenguaje funcional (Wilkinson 1998). En general, los niveles lingüísticos más comprometidos son el semántico y el pragmático, mientras que a nivel fonológico y sintáctico se puede destacar algún tipo de retraso, pero no tan invalidante como el que se detecta en otras competencias (Prizant 1983).

El lenguaje autista se caracteriza por la gran heterogeneidad en sus manifestaciones lingüísticas, sin embargo, una de sus características recurrentes es la presencia de ecolalias². Se pueden distinguir tres tipos principales de ecolalia: la inmediata, la diferida y la matizada. La ecolalia inmediata consiste en la repetición de palabras o expresiones que se han escuchado inmediatamente antes. Las ecolalias diferidas, en cambio, son repeticiones que tienen lugar después de un tiempo con respecto a su emisión. Por lo tanto, la ecolalia inmediata implica el empleo de la memoria a corto plazo, mientras que para realizar una ecolalia diferida el niño tiene que recuperar información de la memoria a largo plazo (Prizant 1983). Una ecolalia matizada, en cambio, es la repetición de una palabra o expresión a la que el niño aporta alguna

\footnotetext{
${ }^{2}$ Una ecolalia es una "perturbación del lenguaje que consiste en repetir el enfermo involuntariamente una palabra o frase que acaba de pronunciar él mismo u otra persona en su presencia” (DLE 2021). Este fenómeno es uno de los más estudiados en el contexto de los trastornos del espectro autista, ya que se puede encontrar en casi el $75 \%$ de esos pacientes que han logrado desarrollar un lenguaje verbal (Prizant 1983).
} 
modificación, cuyo resultado puede llevar a una persona no experta a pensar que es una articulación autónoma, propia del sujeto, y no una repetición modificada.

García de la Torre (2002: 413) afirma que:

La ecolalia es un fenómeno normal en las primeras etapas del desarrollo del lenguaje (aproximadamente hasta los tres años). Sin embargo, en el niño autista dura la ecolalia hasta edades más avanzadas, ocurre con mayor consistencia y no tiene propósito comunicativo. Las imitaciones no son sólo verbales, sino también gestuales.

Sin embargo, otros autores cuestionan la ausencia de intención comunicativa en las ecolalias y aportan pruebas que demuestran que este fenómeno puede tener algún fin comunicativo.

A la hora de hablar de la intención comunicativa en las ecolalias, hay que distinguir las inmediatas de las diferidas. Efectivamente, la mayoría de los investigadores considera que los niños emplean las ecolalias inmediatas sin comprender realmente su significado y sin una intención comunicativa clara. Sin embargo, algunos estudios señalan que este tipo de ecolalia sería una forma de copiar el habla del interlocutor o una estrategia sencilla para intentar mantener la interacción social con el mismo. Además, este tipo de repetición puede emplearse para reafirmar lo que se dijo con anterioridad (Prizant 1983).

Por otra parte, la ecolalia diferida también se ha considerado como una repetición sin significado. Sin embargo, en varios estudios se ha subrayado que esta forma de ecolalia puede servir para distintos fines comunicativos. En efecto, una investigación sobre 400 articulaciones ecolálicas y diversos comportamientos no verbales relacionados con estas estableció catorce funciones diferentes, tanto interactivas como no interactivas, en las ecolalias. Asimismo, las ecolalias diferidas se pueden considerar un ejemplo de procesamiento gestáltico del lenguaje, de hecho, parece que los niños autistas utilizan esta forma de repetición cuando se presenta una situación similar a aquella en la que aprendieron la expresión empleada. Dicha semejanza en las situaciones de enunciación se puede basar en la asociación de la expresión a factores ambientales, a estados de ánimo del niño, o también a experiencias pasadas, como un episodio de dolor físico (Prizant 1983).

Otro fenómeno típico del lenguaje autista es la inversión pronominal: esta se puede considerar una consecuencia del proceso gestáltico de adquisición del lenguaje y del uso de ecolalias diferidas. De hecho, muchas veces el niño se refiere a sí mismo usando los pronombres de segunda o tercera persona singular y esto se debe a que se están reproduciendo 
fragmentos de habla ajena: por ejemplo, puede decir "él está cansado" en lugar de "yo estoy cansado", porque repite las palabras que su madre o su padre emitieron (Prizant 1983).

En el nivel pragmático, que refleja el uso social del lenguaje y que es una de las áreas más afectadas en el sujeto autista, se pueden destacar patrones peculiares en el uso del lenguaje (Wilkinson 1998); por ejemplo, se puede notar cierta dificultad en la gestión de los turnos de habla y la tendencia a hacer preguntas de forma persistente. Asimismo, en este nivel lingüístico se nota "la ausencia de impulso para comunicarse verbalmente, gestualmente o por escrito, hablar sin intención comunicativa, hablar sin entablar contacto visual o dando la espalda al interlocutor" (García de la Torre 2002: 413-414).

Por último, cabe destacar una característica general del trastorno del espectro autista que se presenta también en el lenguaje: la adherencia a rutinas estrictas y a rituales rígidos. Como se especifica en el DSM-V, una persona con TEA mantiene una rutina inflexible con rituales estrictos de comportamiento tanto verbal como no verbal (Biondi y American Psychiatric Association 2014). Esta adhesión total a una secuencia lingüística específica se manifiesta como una rutina discursiva y de interacción social estricta. Si el acto comunicativo sufre modificaciones o cambios inesperados, debido a la necesidad de ajustar el discurso a las circunstancias a través de un proceso analítico, esto puede chocar con la forma gestáltica con la que el niño autista suele comunicarse, de ahí que le resulte complicado mantener la conversación (Prizant 1983).

\subsubsection{La evaluación del lenguaje}

Como afirma Tager-Flusberg (2004: 78),

no single language phenotype defines autism. Rather, there are several distinct phenotypes, which include children with normal linguistic (but not pragmatic) skills and children whose phenotype is the same as SLI [Specific Language Impairment].

A la hora de enfrentarse con un caso de autismo, es importante crear un perfil específico e individual de su lenguaje, que permita destacar puntos fuertes y débiles de cada una de las competencias lingüísticas (Wilkinson 1998). Puyuelo, Rondal y Wiig (2000: 33) afirman que:

La evaluación del lenguaje infantil se realiza para averiguar qué conductas lingüísticas están alteradas y en qué grado, pudiéndose considerar la evaluación como el acto de recoger y analizar información con el objetivo de valorar problemas específicos $y$, además, que esta información sirva para planificar las necesidades educativas específicas del caso. 
Los principales aspectos del lenguaje que se observan en el proceso de evaluación son la competencia fonético-fonológica, la morfológica, la sintáctica, la semántica y la pragmática; asimismo, se lleva a cabo un análisis del discurso y se evalúan los aspectos metalingüísticos (Puyuelo, Rondal y Wiig 2000). Sin embargo, a la hora de evaluar el lenguaje de un niño, hay que considerar muchos factores. Según la clasificación propuesta en el A-RE-HA (Análisis del Retraso del Habla), hay que diferenciar tres formas de desarrollo lingüístico: la normal; la lenta que, aunque tarde más, sigue la evolución que le corresponde; y la "retrasada, que fija procesos o estrategias de simplificación que dificultarán su posterior modificación, especialmente si sale del periodo sensible con recursos inapropiados" (Aguilar Mediavilla y Serra Raventós 2007b: 19).

En segundo lugar, hay que incluir en la evaluación otros factores como el contexto lingüístico del niño. Si los familiares presentan un habla defectuosa o dialectal, habría que valorar, en el caso de que el niño produzca una estructura de forma incorrecta, si es patológica o aprendida. También hay que tener en cuenta posibles situaciones de bilingüismo, los factores clínicos, educativos, ambientales, lingüísticos, así como las dinámicas familiares, los desplazamientos largos y todo elemento que pueda influir sobre el lenguaje del paciente (Aguilar Mediavilla y Serra Raventós 2007b).

Para realizar la evaluación del lenguaje existen herramientas específicas para describir, analizar e interpretar los datos obtenidos. Por un lado, existen pruebas psicolingüísticas estandarizadas que proporcionan datos cuantitativos y suelen enfocarse sobre uno o varios aspectos del lenguaje. Por otro lado, hay pruebas psicolingüísticas no estandarizadas que se usan para observar las conductas comunicativas de los pacientes en un contexto natural. En este caso, se graba el momento de administración de la prueba en formato audiovisual y se analiza la manera de interactuar del sujeto. Una de las ventajas más importantes de este tipo de pruebas es su versatilidad a la hora de analizar la comunicación del paciente. Sin embargo, también se destacan desventajas notables como la cantidad de tiempo que requiere la administración de este tipo de pruebas y la dificultad a la hora de elegir los parámetros que se van a evaluar (Codesido García 2006).

Cabe mencionar también la presencia de un tercer grupo de pruebas, los cuestionarios o registros de observación. En este caso, se proporciona a los padres o a las personas más cercanas al paciente una batería de preguntas basadas en comportamientos prototípicos normalizados para que, a través de las respuestas, el investigador pueda localizar el nivel de desarrollo del sujeto con respecto a la línea evolutiva (Codesido García 2006). 
Después de realizar las pruebas necesarias para evaluar el lenguaje del paciente, se debe plantear qué tipo de intervención hay que llevar a cabo. A lo largo de los años se han experimentado e implementado varios tipos de intervención en el tratamiento del lenguaje en casos de autismo, sin embargo, sigue habiendo controversia sobre cuáles son los métodos más adecuados (Wilkinson 1998).

\section{La comunicación en español en niños autistas: estudio de caso}

\subsection{Metodología de estudio}

El estudio de caso que se presenta a continuación se realizó entre el 24 y el 31 de enero de 2020 en el Colegio Lope de Vega de Alcalá de Henares (Madrid), que cuenta con un equipo de docentes especializados y un programa específico para la educación de niños con TEA. Para respetar la privacidad de las personas implicadas, se mantendrán ocultos sus nombres y se hará referencia a ellos con nombres ficticios ${ }^{3}$. La investigación se llevó a cabo con el fin de analizar el lenguaje y la competencia lingüística de uno de los alumnos con TEA del colegio, para comprobar si los datos recogidos reflejaban las peculiaridades lingüísticas asociadas al trastorno y documentadas en la bibliografía.

Para cumplir los objetivos propuestos, se eligió articular el estudio en tres fases. En primer lugar, para determinar el historial clínico del sujeto, se suministró a sus padres un cuestionario a través del que pudieron proporcionar información importante sobre la salud de su hijo. Se eligió realizar este pasaje de la investigación de forma escrita privada porque permitía recoger información más detallada y fiable.

En segundo lugar, se llevó a cabo una primera fase de observación del comportamiento espontáneo del niño en un contexto muy familiar para él, su colegio, tanto en el aula específica para los alumnos con TEA como en su aula de referencia4 ${ }^{4}$. Se observó su manera de interactuar tanto con las docentes como con sus compañeros, tomando nota de todas las acciones y

\footnotetext{
${ }^{3}$ Todos los datos recogidos durante la investigación han sido tratados según la ley aplicable en España (Ley Orgánica de Protección de Datos, 3/2018 de 5 de diciembre, acorde con el Reglamento General de Protección de Datos, RGPD UE 2016/976).

${ }^{4}$ En el aula de referencia, los niños con autismo siguen las clases junto al resto del alumnado y desarrollan las mismas actividades con la ayuda de una profesora de apoyo. En el aula específica para alumnos con TEA, los niños realizan unas sesiones diarias de una hora cada una durante las que se proponen tareas específicas para mejorar sus habilidades lingüísticas, motrices y de atención. Las sesiones están pensadas para uno o dos alumnos a la vez que tienen el mismo nivel de desarrollo intelectual, de manera que se puedan realizar tareas iguales o parecidas.
} 
comportamientos anómalos. Asimismo, se recogió una muestra de habla espontánea del niño para analizar su nivel lingüístico en un contexto natural.

Sucesivamente, en la segunda fase del estudio, se administraron cuatro pruebas para evaluar el nivel lingüístico del niño: en concreto, se recogieron datos para establecer su perfil a nivel fonético-fonológico y, de forma más simple, a nivel morfológico. Cada prueba constaba de material específico y evaluaba diferentes aspectos del habla del sujeto. Todas las pruebas presentaban material visual, puesto que el niño ya estaba acostumbrado a trabajar con imágenes; de este modo, el alumno se encontró con material nuevo pero, al mismo tiempo, familiar, y esto se tradujo en un nivel mayor de colaboración por su parte.

Las cuatro pruebas que se administraron son la prueba de rastreo, la prueba de articulación de pares mínimos, la prueba de discriminación de contrastes y la prueba de morfología. A continuación, se describen las características y el método de administración de cada una.

Como se explica en el A-RE-PA (Aguilar Mediavilla y Serra Raventós 2007a), la prueba de rastreo consiste en proporcionar al paciente una serie de imágenes que este tendrá que denominar una a una para que se pueda determinar su competencia fonética y fonológica y averiguar si es posible destacar algún tipo de inmadurez o retraso en su desarrollo. La prueba evalúa tres niveles estructurales: el nivel de la palabra, el silábico y, finalmente, el segmental. En el nivel de la palabra, el objetivo es comprobar si el niño logra articular todas las sílabas de la palabra y observar si se produce algún tipo de omisión o asimilación silábica o si durante la articulación el paciente produce cambios en la posición de las sílabas en la palabra. En el nivel de la sílaba, se pretende analizar el tipo de estructuras silábicas que el niño sabe producir y utilizar: por ejemplo, se observa si logra articular una sílaba con una coda consonántica o con un grupo consonántico en su interior. Por último, en el nivel segmental, se analizan los fonemas adquiridos por el niño. Para realizar la prueba se empleó una muestra de 28 imágenes extraídas del A-RE-PA (Aguilar Mediavilla y Serra Raventós 2007a) ${ }^{5}$, cada una correspondiente a una palabra. Junto a cada dibujo (p. ej. Figura 1) se encuentra la palabra que corresponde a la imagen representada, que el niño tiene que articular, y una frase que explica brevemente qué objeto aparece en la lámina; quien administra la prueba puede utilizar este enunciado (u

\footnotetext{
${ }^{5}$ Puesto que solo se pudo encontrar el volumen entero en catalán, las palabras y las explicaciones a estas relacionadas se han traducido al español y los elementos analizados en cada una (fonemas, diptongos, grupos consonánticos, sílabas) se han adaptado al inventario lexical en castellano.
} 
otro tipo de explicación que se considere más adecuada según el caso concreto) para ayudar al niño si no reconoce qué se representa en el dibujo.
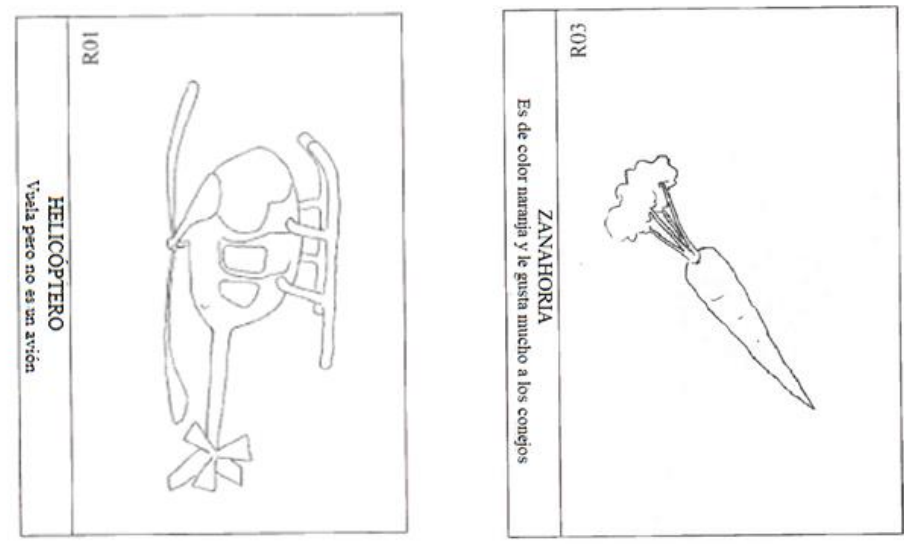

Figura 1. Ejemplo de dos imágenes/láminas empleadas para la realización de la prueba. En mayúsculas se lee la palabra que el paciente tiene que articular; en minúsculas una posible explicación de la misma (Aguilar

Mediavilla y Serra Raventós $2007 a$ - traducción de las palabras al español realizada por la autora).

Cada ítem presenta ciertas características en su composición fonética, como un diptongo o un determinado número de sílabas, cuya articulación correcta o incorrecta por parte del niño permitirá evaluar varios aspectos de su habla.

La segunda prueba que se propuso durante la investigación fue diseñada por la autora de este estudio basándose en los materiales proporcionados para la prueba de discriminación de contrastes en el A-RE-PA (Aguilar Mediavilla y Serra Raventós 2007a). Se hará referencia a esta como prueba de articulación de pares mínimos y su objetivo es evaluar la capacidad del niño de articular sustantivos que constituyen un par mínimo, esto es, que tienen los mismos fonemas en su interior menos uno (p. ej. fuente y puente). En el análisis de los datos obtenidos a través de esta prueba solo se evaluó el nivel segmental de las palabras para averiguar si el niño tenía dificultades a la hora de articular un par mínimo.

Para la realización de la prueba se emplearon 10 láminas: cada una de estas contiene dos imágenes, las que constituyen uno de los pares mínimos analizados (p. ej. Figura 2). Se proporcionaron al niño las diez láminas de forma sucesiva, para que denominara los objetos que aparecían en las mismas. 


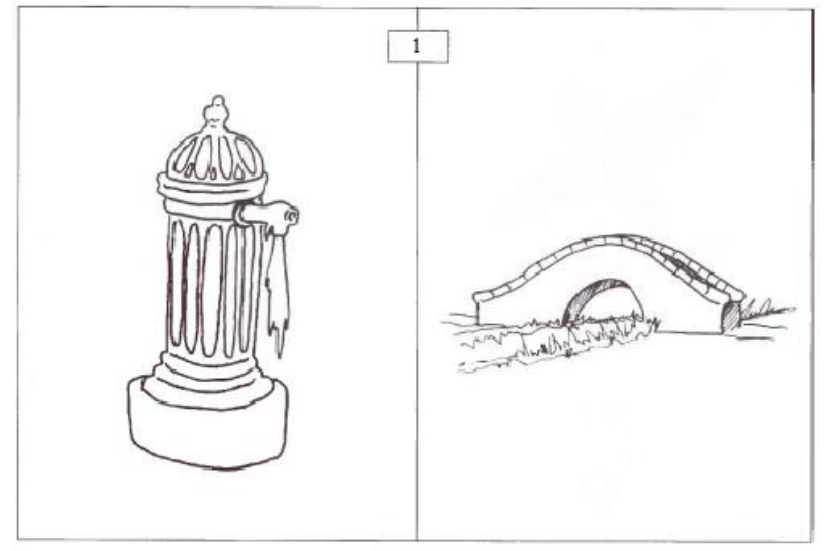

Figura 2. Ejemplo de una lámina utilizada en la prueba. El par mínimo analizado aquí es fuente-puente (Aguilar Mediavilla y Serra Raventós 2007a).

La tercera prueba también se extrajo del A-RE-PA (Aguilar Mediavilla y Serra Raventós 2007a) ${ }^{6}$. Como se especifica en el manual mismo, esta se conoce como prueba de discriminación de contrastes y tiene como objetivo comprobar si el niño puede distinguir los fonemas de su lengua al escucharlos. Al contrario de las pruebas utilizadas anteriormente, esta permitió analizar las habilidades de discriminación fonológica del niño y no las de producción. En el contexto de la investigación, se decidió proporcionar al niño palabras con fonemas conocidos y desconocidos, para poder profundizar en el análisis de su fonética. En todo caso, al analizar los resultados de la prueba se prestó particular atención a aquellos fonemas donde se destacaron dificultades de articulación en las pruebas anteriores. Para la realización de la prueba se emplearon las mismas láminas utilizadas en la prueba de articulación de pares mínimos, ya que se querían analizar los mismos sonidos: se le preguntó al niño antes dónde estaba uno de los dos objetos de la lámina (véase Figura 2; p.ej. “¿Dónde está la fuente?”) y luego el otro (p.ej. “¿Y dónde está el puente?”) para comprobar si indicaba el objeto correcto y podía, por lo tanto, discriminar correctamente el contraste analizado (p. ej. $/ \mathrm{f} /-/ \mathrm{p} /)$.

Se decidió realizar tanto la prueba de articulación de pares mínimos como la de discriminación de contrastes porque se querían analizar tanto las habilidades articulatorias del niño como las de discriminación fonético-fonológica a la hora de enfrentarse con un par mínimo para averiguar si posibles dificultades en una de las capacidades analizadas perjudicaban también la otra.

\footnotetext{
${ }^{6}$ Puesto que solo se pudo encontrar el volumen entero en catalán, las palabras y los contrastes analizados en la prueba se han adaptado al inventario fonético castellano.
} 
Finalmente, se decidió analizar los conocimientos morfológicos del niño a través de la prueba de morfología. Esta fue diseñada autónomamente por la autora basándose en el manual de Puyuelo, Rondal y Wiig (2000), donde se comentaban algunos criterios de evaluación de las capacidades morfológicas de un paciente, para poder hacer una primera y sumaria evaluación del desarrollo morfológico del niño. El objetivo de esta prueba final es analizar, aunque de forma no exhaustiva, las capacidades del niño de reconocer el fenómeno de la pluralidad y su habilidad al utilizar los morfemas flexivos para la formación del plural.

Para esta prueba se ha diseñado un conjunto de diez láminas (p. ej. Figura 3) en las que a la izquierda, aparece una imagen que representa un objeto en singular, a la derecha la misma imagen repetida varias veces para representar la pluralidad del objeto.

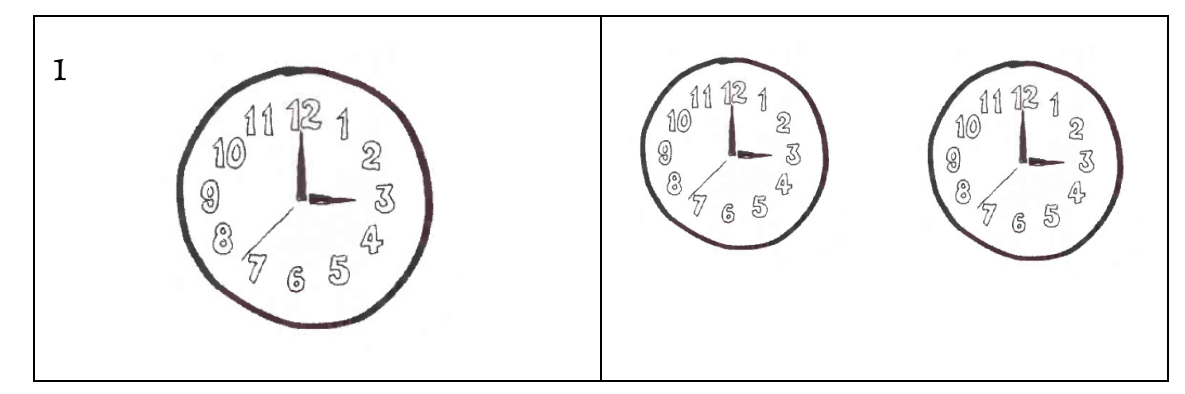

Figura 3. Ejemplo de una lámina utilizada en la prueba de morfología (Aguilar Mediavilla y Serra Raventós 2007a).

Para la realización de la prueba, se eligió mantener un método parecido a los empleados anteriormente y preguntar al niño: “qué hay aquí?”, para que pudiera producir su respuesta sin influencias del exterior. La profesora podía decirle el nombre correcto si por algún motivo el niño desconocía el objeto representado en la imagen en singular, evitando, sin embargo, decirle la forma plural del sustantivo, ya que esa era el objeto de análisis de la prueba.

Los resultados de las pruebas se comentarán en el apartado 3.3.

\subsection{Primeras observaciones y consideraciones sobre el caso}

El niño objeto de estudio, quien será llamado de aquí en adelante Lope, tenía 4 años y 9 meses cuando se realizó la investigación; el español era su lengua materna y se le había diagnosticado un trastorno del espectro autista. Los padres informaron que sus primeras palabras fueron mamá y agua y las articuló a los 6/7 meses de edad, luego, desde los 8/9 meses hasta los 3 años, hubo un periodo de estancamiento lingüístico, en el que el niño mostraba un lenguaje muy limitado. Asimismo, comunicaron que antes no utilizaba expresiones faciales 
para comunicarse, mientras que desde los 4 años empezó poco a poco a expresar sorpresa, enfado, alegría y tristeza cuando se hacía daño. Por lo que respecta a la comunicación, Lope usaba palabras y gestos para señalar lo que quería; además, según la información proporcionada por los padres, hacía tiempo, si no entendían lo que el niño trataba de decirles, este lloraba con rabia y nervios e incluso daba cabezazos fuertes en el suelo o en la pared, mientras que creciendo dejó de utilizar dichos comportamientos de autolesión, limitándose a gritar y llorar. Por último, Lope podía comprender los estados de ánimo, como el enfado, alegría y tristeza, de las personas que le rodeaban, obedecía a órdenes básicas y sabía identificar y pedir lo que quería.

A través de la observación directa del comportamiento espontáneo del niño, se pudieron recoger más datos acerca de su desarrollo y de la presencia de conductas estereotipadas, sus capacidades sociales, su desarrollo lingüístico y comunicativo. Por lo que respecta a los comportamientos estereotipados, en Lope se pudo destacar la presencia de tres estereotipias mayores. En primer lugar, un gesto muy frecuente que se notó en el periodo de observación fue el de cubrirse los oídos cuando había un ruido fuerte o que le molestaba, por ejemplo, cuando los compañeros gritaban o la maestra hablaba en voz alta. Además, solía frotarse los ojos a menudo y hacer un ruido con la boca y la garganta, como el de un motor, mientras estaba concentrado o, en general, cuando estaba realizando una actividad manual. Cabe destacar que el niño tenía muy buena motricidad fina: estaba aprendiendo a escribir en cursiva, sabía ponerse y apretarse el babi a solas, era capaz de recortar siguiendo las líneas trazadas y sabía crear formas con la plastilina.

Por lo que se refiere a la capacidad de Lope de relacionarse e interactuar con los demás, en el aula de trabajo para alumnos con TEA, el niño estaba generalmente muy tranquilo y comprendía bien las entregas de los ejercicios que se le proporcionaban, realizándolos siguiendo las indicaciones de las profesoras, mientras que en el aula de referencia solía estar más nervioso e inquieto. Además, demostró saber relacionarse con los demás: si quería algo, lo pedía e interactuaba con los otros para la realización de las tareas que se le proponían. No le molestaba el contacto físico, al contrario, muchas veces era él mismo quien lo buscaba, acercándose a los compañeros para abrazarlos o darles besos en las mejillas.

Sin embargo, se pudo notar que, cuando por algún motivo cambiaba su rutina, se ponía muy nervioso y tenía una actitud no colaborativa. Por ejemplo, cuando durante un día de investigación una profesora se puso enferma y acudió una sustituta, Lope no quiso trabajar durante todo el día y no realizó las tareas que normalmente llevaba a cabo con tranquilidad. 


\subsection{Resultados}

Se comentan en este apartado los resultados obtenidos a través de la administración de las cuatro pruebas. Para mantener orden y explicar claramente los datos registrados durante el estudio, se anotarán por separado los resultados de cada prueba.

\subsubsection{Resultados de la prueba de rastreo}

En primer lugar, se describen los resultados de la prueba de rastreo a través del análisis de cada uno de los niveles estudiados. En la columna "niño" se apuntan las producciones lingüísticas de Lope: si aparece solo un ítem, significa que dijo el nombre del objeto siempre de la misma forma. En cambio, si lo articuló de diferentes maneras, estas formas aparecen la una al lado de la otra en la misma columna. En las Tablas 1, 2 y 3 se marcan en rojo los puntos de la estructura de la palabra y de la sílaba donde se notaron errores de producción, así como los fonemas que el niño articuló incorrectamente.

En el nivel de la palabra, Lope no presentaba dificultades particulares a la hora de articular todas las sílabas, independientemente de la extensión de la palabra. Se pudo detectar una sola excepción en la palabra helicóptero, la única en el inventario analizado con una estructura que superaba las 4 sílabas ( 5 sílabas en total), donde se observó la omisión de las sílabas átonas iniciales. Esta anomalía se pudo observar en las cuatro repeticiones de la prueba.

\begin{tabular}{|c|c|c|c|c|c|}
\hline LÁMINA & \multicolumn{2}{|c|}{ TRANSCRIPCIÓN } & NIÑO & $\begin{array}{c}\text { ESTRUCTURA } \\
\text { PALABRA }\end{array}$ & $\begin{array}{c}\text { PROCESOS } \\
\text { PALABRA }\end{array}$ \\
\hline 1 & Helicóptero & [elikóptero] & [kotelo] & A-A-T-A-A & $\begin{array}{c}\text { Omisión de } \\
\text { las sílabas } \\
\text { átonas iniciales }\end{array}$ \\
\hline
\end{tabular}

Tabla 1. Anomalías en el nivel de la palabra.

En el nivel silábico, se pudieron encontrar más problemas: de hecho, se puede afirmar que este es el nivel donde apareció el mayor número de errores. A la hora de analizar el tipo de estructuras silábicas que el niño produjo correcta o incorrectamente, se notó que durante la administración de la prueba produjo siempre correctamente las estructuras VV (vocal-vocal) y VC (vocal-consonante), mientras que articuló las demás de forma incorrecta, al menos en una ocasión. Hay que subrayar que, en la mayoría de los casos, se produjo el mismo tipo de error en las repeticiones de la prueba. 
La competencia lingüística en español (L1) en pacientes con trastorno del espectro autista...

\begin{tabular}{|c|c|c|c|c|c|}
\hline LÁMINA & \multicolumn{2}{|c|}{ TRANSCRIPCIÓN } & \multirow{2}{*}{$\begin{array}{c}\text { NIÑO } \\
\text { [kotelo] }\end{array}$} & \multirow{2}{*}{$\begin{array}{l}\text { ESTRUCTURA } \\
\text { SILÁBICA } \\
\\
\mathrm{v}|\mathrm{cv}| \mathrm{cvc}|\mathrm{cv}| \mathrm{cv}\end{array}$} & \multirow{2}{*}{$\begin{array}{c}\text { PROCESOS } \\
\text { SILÁBICOS } \\
\text { Omisión de } \\
\text { consonante en } \\
\text { posición de coda }\end{array}$} \\
\hline 1 & Helicóptero & [elikóptero] & & & \\
\hline 2 & Chocolate & [tyokoláte] & [okolate] & $\mathrm{cv}|\mathrm{cv}| \mathrm{cv} \mid \mathrm{cv}$ & $\begin{array}{c}\text { Omisión de } \\
\text { consonante en } \\
\text { posición de ataque }\end{array}$ \\
\hline 3 & Zanahoria & [Oanaórja] & [sanaoia] & $\mathrm{cv}|\mathrm{cv}| \mathrm{v} \mid \mathrm{crv}$ & $\begin{array}{c}\text { Omisión de } \\
\text { consonante en } \\
\text { posición de ataque }\end{array}$ \\
\hline 4 & Elefante & [elefánte] & [elefate] & $\mathrm{v}|\mathrm{cv}| \mathrm{cvc} \mid \mathrm{cv}$ & $\begin{array}{c}\text { Omisión de } \\
\text { consonante en } \\
\text { posición de coda }\end{array}$ \\
\hline 7 & Tortuga & [tortúya] & [totuya] & $\mathrm{cvc}|\mathrm{cv}| \mathrm{cv}$ & $\begin{array}{c}\text { Omisión de } \\
\text { consonante en } \\
\text { posición de coda }\end{array}$ \\
\hline 8 & Estrella & [estréKa] & [este $K a] /[$ estreKa] & $\mathrm{vc}|\mathrm{ccv}| \mathrm{cv}$ & $\begin{array}{c}\text { Reducción } \\
\text { del grupo } \\
\text { consonántico }\end{array}$ \\
\hline 11 & Melón & [melón] & [melo] & $\mathrm{cv} \mid \mathrm{cvc}$ & $\begin{array}{c}\text { Omisión de } \\
\text { consonante en } \\
\text { posición de coda }\end{array}$ \\
\hline 16 & Doctor & [doktór] & [doto] & $\mathrm{cvc} \mid \mathrm{cvc}$ & $\begin{array}{c}\text { Omisión de } \\
\text { consonante en } \\
\text { posición de coda }\end{array}$ \\
\hline 18 & Cuerno & [kwérno] & [kweno] & $\mathrm{CVvc} \mid \mathrm{cv}$ & $\begin{array}{c}\text { Omisión de } \\
\text { consonante en } \\
\text { posición de coda }\end{array}$ \\
\hline 21 & Yogur & [joyúr] & [joуu] & $\mathrm{vv} \mid \mathrm{cvc}$ & $\begin{array}{l}\text { Omisión de } \\
\text { consonante en } \\
\text { posición de coda }\end{array}$ \\
\hline
\end{tabular}




\begin{tabular}{|c|c|c|c|c|c|}
\hline 22 & Fútbol & [fút $\beta o l]$ & [fut $\beta \mathrm{ol}] /[\mathrm{fu} \beta \mathrm{ol}]$ & $\mathrm{cvc} \mid \mathrm{cvc}$ & $\begin{array}{c}\text { Omisión de } \\
\text { consonante en } \\
\text { posición de coda }\end{array}$ \\
\hline 23 & Tambor & [tambór] & [tablo] & $\mathrm{cvc} \mid \mathrm{cvc}$ & $\begin{array}{c}\text { Omisión de } \\
\text { consonante en } \\
\text { posición de coda }\end{array}$ \\
\hline 24 & Timbre & [tímbre] & [tibre] & $\mathrm{cvc} \mid \mathrm{ccv}$ & $\begin{array}{c}\text { Omisión de } \\
\text { consonante en } \\
\text { posición de coda }\end{array}$ \\
\hline 25 & Reina & [réjna] & [ejna] & $\mathrm{cvv} \mid \mathrm{cv}$ & $\begin{array}{c}\text { Omisión de } \\
\text { consonante en } \\
\text { posición de ataque }\end{array}$ \\
\hline 28 & Carne & [kárne] & [kame] & $\mathrm{cvc} \mid \mathrm{cv}$ & $\begin{array}{l}\text { Omisión de } \\
\text { consonante en } \\
\text { posición de coda }\end{array}$ \\
\hline
\end{tabular}

Tabla 2. Anomalías en el nivel de la sílaba.

Como se muestra en la Tabla 2, el obstáculo mayor para el niño fue la producción de las consonantes sobre todo en posición de coda silábica. Ejemplos de esto se pudieron hallar en la articulación de las palabras helicóptero (lámina 1), tortuga (lámina 7), yogur (lámina 21), entre otras. Asimismo, se destacaron algunas omisiones de consonante en posición de ataque silábico, como en chocolate (lámina 2), zanahoria (lámina 3) y reina (lámina 25). Además, se notó en tres ocasiones una reducción del grupo consonántico en la palabra estrella (lámina 8); sin embargo, el último día, Lope logró articular correctamente el grupo consonántico sin la ayuda de las profesoras. Otro caso particular es el de la palabra fútbol: el niño la produjo correctamente dos veces, cuando todavía no lograba entender autónomamente qué representaba el dibujo y repetía la palabra después de que se la hubiera dicho la profesora, e incorrectamente dos veces, cuando ya se acordaba de que el sujeto era el fútbol.

En el nivel fonético, en general se notó un buen desarrollo. Se destacó cierta dificultad en la producción del fonema / $\mathrm{r} /$ : en muchos casos el niño omitía dicho fonema, como se puede notar en la Tabla 2, sin embargo, en otros casos lo producía como /1/. Este es un ejemplo de lateralización de vibrante simple y en la muestra recogida se puede apreciar la aparición de este fenómeno tres veces. Además, en el caso de la palabra tambor (lámina 23), después de la lateralización de este fonema, se registró una metátesis del mismo, siendo el resultado de este 
proceso la articulación de la palabra como/tablo/. En este caso, tuvo lugar también un proceso de simplificación silábica, ya que la desaparición de la consonante /m/ es un ejemplo de omisión de consonante en posición de coda silábica.

Se pudo notar también, durante la prueba y durante la observación general de las habilidades del niño, cierta dificultad en la producción de $/ \theta /$ : de hecho, Lope solía producir este fonema como /s/, dando lugar así a un proceso de posteriorización. Por lo que respecta al ejemplo de anteriorización del fonema / $\mathrm{n}$ / que se realizó en la articulación de carne (lámina 28), cabe comentar que este fue el único caso, a lo largo de la investigación, en el que se pudo detectar una producción incorrecta del fonema en cuestión. Por lo tanto, es posible que dicho fenómeno de simplificación se deba a la presencia del fonema /r/ al lado de /n/.

\begin{tabular}{|c|c|c|c|c|c|}
\hline LÁMINA & \multicolumn{2}{|c|}{ TRANSCRIPCIÓN } & NIÑO & FONEMAS & PROCESOS \\
\hline 1 & Helicóptero & [elikóptero] & [kotelo] & $p-r$ & $\begin{array}{c}\text { Lateralización } \\
\text { de vibrante simple }\end{array}$ \\
\hline 12 & Pera & [péra] & [pela] & $p-r$ & $\begin{array}{c}\text { Lateralización } \\
\text { de vibrante simple }\end{array}$ \\
\hline 23 & Tambor & [tambór] & [tablo] & $m b-r$ & $\begin{array}{c}\text { Lateralización } \\
\text { de vibrante simple y } \\
\text { metátesis de dicha } \\
\text { consonante }\end{array}$ \\
\hline 27 & Pez & [pé $\theta$ ] & {$[$ pe $\theta] /[$ pes] } & $\theta$ & Posteriorización \\
\hline 28 & Carne & [kárne] & [kame] & $\mathrm{rn}$ & Anteriorización \\
\hline
\end{tabular}

Tabla 3. Resumen de anomalías en el nivel fonético.

\subsubsection{Resultados de la prueba de articulación de pares mínimos}

En la Tabla 4 se anotan los resultados de la prueba de articulación de pares mínimos: si Lope articuló las palabras de la misma manera todas las veces, solo aparece un ítem en la columna correspondiente; si las dijo de distintas formas, se registraron juntas en la misma columna.

En un nivel más general, se pudieron notar las mismas dificultades en la articulación de los grupos consonánticos y del fonema / $/$ que se destacaron durante la prueba de rastreo. 
En cuanto a la oposición concreta entre los pares mínimos, se destacó que a pesar de la presencia de dificultades articulatorias de algunos fonemas, el niño era consciente de que eran sonidos distintos de la lengua. Este es el caso de la oposición /r/-/s/ (lámina 6), donde el niño reconoció la presencia de fonemas distintos, sin embargo, no sabiendo articular correctamente el sonido /r/, lo produjo como /l/, lateralizando la vibrante simple. En el caso de la lámina 8, el niño logró articular el fonema /ð/ correctamente solo dos veces, mientras que produjo la palabra como /bola/ en dos ocasiones. Cabe destacar también que, cuando vio la imagen de la bota, articuló enseguida /botas/ y siguió utilizando la forma plural del sustantivo durante todas las administraciones de la prueba, a pesar de las correcciones: es posible que esto se deba al hecho de que en el habla cotidiana esta palabra suele emplearse en plural.

El caso más interesante se destacó en la oposición presente en la lámina 9 (/g/-/b/). De hecho, se notó cierta dificultad en la articulación de la /g/ inicial: el niño articuló la palabra como /ota/ tres veces y una como/bota/. Este fue el único caso donde Lope no logró discriminar el par mínimo y articuló las palabras de la misma forma (/bota/).

\begin{tabular}{|c|c|c|c|c|c|}
\hline LÁMINA & CONTRASTE & PALABRA & NIÑO & PALABRA & NIÑO \\
\hline 1 & $\mid \mathrm{f} /-/ \mathrm{p} /$ & Fuente /fwénte/ & /fwete/ & Puente /pwénte/ & /pwete/ \\
\hline 2 & $|\mathrm{t} /-| \mathrm{t} \mid$ & Plancha /plántfa/ & /latfa/ & Planta /plánta/ & /lanta/ \\
\hline 3 & $/ \mathrm{b} /-/ \mathrm{m} /$ & Bar /bár/ & /ba/ & Mar /már/ & /ma/ \\
\hline 4 & $/ \mathrm{s} /-/ \mathrm{m} /$ & Cama /kása/ & /kama/ & Casa /kása/ & /kasa/ \\
\hline 5 & $/ 1 /-/ \mathrm{m} /$ & Lago /lágo/ & /lago/ & Mago /mágo/ & /mago/ \\
\hline 6 & $|\mathrm{r} /-/ \mathrm{s}|$ & Cara /cára/ & /kala/ & Casa /cása/ & /kasa/ \\
\hline 7 & $/ \mathrm{b} /-/ \mathrm{p} /$ & Vino /bíno/ & /bino/ & Pino/píno/ & /pino/ \\
\hline 8 & $|\partial /-| t \mid$ & Boda /bóða/ & /boða/-/bola/ & Bota /bóta/ & /botas/ \\
\hline 9 & $|g /-| b \mid$ & Gota /góta/ & /ota/-/bota/ & Bota /bóta/ & /botas/ \\
\hline 10 & $|\theta|-|s|$ & Caza /cá a a/ & /kasa/ & Casa /cása/ & /kasa/ \\
\hline
\end{tabular}

Tabla 4. Muestra fonológica de la articulación de pares mínimos. 


\subsubsection{Resultados de la prueba de discriminación de contrastes}

En la columna "Respuesta" de la Tabla 5, se indicó si el niño contestó correctamente o no a las preguntas. Como se puede apreciar, Lope logró discriminar todos los sonidos analizados sin cometer errores. Por lo tanto, se puede afirmar que la incapacidad del niño de articular correctamente algunos fonemas, como /g/ en el contraste /g/-/b/, no afecta su habilidad de distinguirlos al escucharlos.

\begin{tabular}{|c|c|c|c|c|}
\hline \multicolumn{5}{|c|}{ MODO DE ARTICULACIÓN } \\
\hline \multicolumn{5}{|c|}{ Fricativas/africadas frente a oclusivas } \\
\hline Lámina & Primera & Segunda & Contraste & Respuesta \\
\hline 1. & fuente / fwénte/ & puente /pwénte/ & $\mid \mathrm{f} /-/ \mathrm{p} /$ & $\checkmark$ \\
\hline 2. & plancha /plántya/ & planta /plánta/ & $|\mathrm{t}|-|\mathrm{t}|$ & $\checkmark$ \\
\hline \multicolumn{5}{|c|}{ Oclusivas frente a nasales } \\
\hline Lámina & Primera & Segunda & Contraste & Respuesta \\
\hline 3. & bar /bár/ & mar/már/ & $/ \mathrm{b} /-/ \mathrm{m} /$ & $\checkmark$ \\
\hline \multicolumn{5}{|c|}{ Fricativas frente a nasales } \\
\hline Lámina & Primera & Segunda & Contraste & Respuesta \\
\hline 4. & casa /kása/ & cama /káma/ & $/ \mathrm{s} /-/ \mathrm{m} /$ & $\checkmark$ \\
\hline \multicolumn{5}{|c|}{ Líquidas frente a nasales } \\
\hline Lámina & Primera & Segunda & Contraste & Respuesta \\
\hline 5. & lago /lágo/ & mago /mágo/ & $/ 1 /-/ \mathrm{m} /$ & $\checkmark$ \\
\hline \multicolumn{5}{|c|}{ Líquidas frente a fricativas } \\
\hline Lámina & Primera & Segunda & Contraste & Respuesta \\
\hline 6. & cara /kára/ & casa /kása/ & $|\mathrm{r} /-| \mathrm{s} \mid$ & $\checkmark$ \\
\hline \multicolumn{5}{|c|}{ SONORIDAD } \\
\hline \multicolumn{5}{|c|}{ Sonorización frente a insonorización de las oclusivas } \\
\hline
\end{tabular}




\begin{tabular}{|c|c|c|c|c|}
\hline Lámina & Primera & Segunda & Contraste & Respuesta \\
\hline 7. & vino /bíno/ & pino /píno/ & $/ \mathrm{b} /-/ \mathrm{p} /$ & $\checkmark$ \\
\hline 8. & boda /bóda/ & bota /bóta/ & $|ð /-| t /$ & $\checkmark$ \\
\hline \multicolumn{5}{|c|}{ PUNTO DE ARTICULACIÓN } \\
\hline \multicolumn{5}{|c|}{ Oclusivas frontales frente a posteriores } \\
\hline Lámina & Primera & Segunda & Contraste & Respuesta \\
\hline 9. & gota /góta/ & bota /bóta/ & $\mid g /-/ b /$ & $\checkmark$ \\
\hline \multicolumn{5}{|c|}{ Fricativas frontales frente a posteriores } \\
\hline Lámina & Primera & Segunda & Contraste & Respuesta \\
\hline 10. & $\operatorname{caza} /$ cá $\theta \mathrm{a} /$ & casa /kása/ & $|\theta|-|s|$ & $\checkmark$ \\
\hline
\end{tabular}

Tabla 5. Resultados de la prueba de discriminación de contrastes.

\subsubsection{Resultados de la prueba de morfología}

En la Tabla 6 se registran todas las producciones del niño durante la administración de la prueba, apuntando al lado el número de veces en las que formó el plural correctamente, semi-correctamente (es decir, cuando intentó formar el plural añadiendo una -e al sustantivo en singular en esos casos donde la formación del plural implique añadir el sufijo -es a la forma singular) o incorrectamente.

En general, se notó que el niño no sabía cómo formar el plural de las palabras y, por lo tanto, utilizar la flexión nominal. Solo en algunos casos intentó la formación del plural y solo en un número de casos muy limitado acertó en el intento. Analizando en concreto el caso de cada lámina, se notó una producción incorrecta, en todas las ocasiones, en las láminas 2 (fresa), 3 (casa), 4 (pera), 8 (coche), 9 (gato) y 10 (guantes). En todos los casos menos en la lámina 10, el niño mantuvo la forma del sustantivo en singular. En cambio, en el caso de guante-guantes, utilizó el plural de la palabra también para indicar el singular, probablemente debido al hecho de que este sustantivo, en el habla cotidiana, se usa en la mayoría de los casos en plural.

En lo que respecta a las láminas 1 (reloj) y 6 (dragón) se ha podido observar un intento de formación del plural, en el primer caso, dos veces, y en el segundo, una vez: de hecho, el niño añadió una -e a la forma singular del sustantivo cuando tenía que indicar el plural. 
Solo en dos casos el niño logró formar correctamente el plural: en la lámina 5 (lunas) y en la lámina 7 (niñas). Puesto que logró articular correctamente los plurales solo una vez en cada caso, no se puede afirmar con seguridad si consiguió la articulación correcta por casualidad, esto es, si se acordaba de algunas correcciones que la profesora había hecho durante las administraciones anteriores, o si fue una elección voluntaria.

\begin{tabular}{|c|c|c|c|}
\hline NÚMERO & LÁMINA & NIÑO & RESPUESTA \\
\hline 1 & Reloj-relojes & $\begin{array}{l}\text { 1. Reloj - reloj } \\
\text { 2. Reloj-reloj } \\
\text { 3. Reloj- reloje } \\
\text { 4. Reloj-reloje }\end{array}$ & $\begin{array}{l}2 \text { veces incorrecta, } 2 \text { veces } \\
\text { semi-correcta }\end{array}$ \\
\hline 2 & Fresa - fresas & $\begin{array}{l}\text { 1. Fresa - fresa } \\
\text { 2. Fresa - fresa } \\
\text { 3. Fresa - fresa } \\
\text { 4. Fresa - fresa }\end{array}$ & 4 veces incorrecta \\
\hline 3 & Casa - casas & $\begin{array}{l}\text { 1. Casa - casita } \\
\text { 2. Casa - casa } \\
\text { 3. Casa - casa } \\
\text { 4. Casa - casita }\end{array}$ & 4 veces incorrecta \\
\hline 4 & Pera - peras & $\begin{array}{l}\text { 1. Pera - pera } \\
\text { 2. Pera - pera } \\
\text { 3. Pera - pera } \\
\text { 4. Pera - pera }\end{array}$ & 4 veces incorrecta \\
\hline 5 & Luna - lunas & $\begin{array}{l}\text { 1. Luna - luna } \\
\text { 2. Luna - luna } \\
\text { 3. Luna - luna } \\
\text { 4. Luna - lunas }\end{array}$ & $\begin{array}{l}3 \text { veces incorrecta, } \\
1 \text { vez correcta }\end{array}$ \\
\hline 6 & Dragón - dragones & $\begin{array}{l}\text { 1. Dragón - dragón } \\
\text { 2. Dragón - dragón }\end{array}$ & $\begin{array}{c}3 \text { veces incorrecta, } 1 \mathrm{vez} \\
\text { semi-correcta }\end{array}$ \\
\hline
\end{tabular}




\begin{tabular}{|c|c|c|c|}
\hline & & $\begin{array}{l}\text { 3. Dragón - dragone } \\
\text { 4. Dragón - dragón }\end{array}$ & \\
\hline 7 & Niña - niñas & $\begin{array}{l}\text { 1. Niña - niña } \\
\text { 2. Niña - niña } \\
\text { 3. Niña - niña } \\
\text { 4. Niña - niñas }\end{array}$ & $\begin{array}{c}3 \text { veces incorrecta, } 1 \text { vez } \\
\text { correcta }\end{array}$ \\
\hline 8 & Coche - coches & $\begin{array}{l}\text { 1. Coche - coche } \\
\text { 2. Coche - coche } \\
\text { 3. Coche - coche } \\
\text { 4. Coche - coche }\end{array}$ & 4 veces incorrecta \\
\hline 9 & Gato - gatos & $\begin{array}{l}\text { 1. Gato - gato } \\
\text { 2. Gato - gato } \\
\text { 3. Gato - gato } \\
\text { 4. Gato - gato }\end{array}$ & 4 veces incorrecta \\
\hline 10 & Guante - guantes & $\begin{array}{l}\text { 1. Guantes - guantes } \\
\text { 2. Guantes - guantes } \\
\text { 3. Guantes - guantes } \\
\text { 4. Guantes - guantes }\end{array}$ & 4 veces incorrecta \\
\hline
\end{tabular}

Tabla 6. Resultados de la prueba de morfología.

\subsection{Perfil lingüístico del estudio de caso}

En general, durante el trabajo de investigación se pudo notar que el niño presentaba buenas capacidades lingüísticas. El desarrollo de su fonética era notable, como se comprobó tanto a través de las pruebas como a través de la recogida de habla espontánea. Para determinar su nivel de competencia, se tomó como referencia el Cuadro 3 del A-RE-HA: "Evolución en la articulación correcta (90\% de sujetos) de los segmentos" (Aguilar Mediavilla y Serra Raventós 2007b: 27). En primer lugar, hay que hacer algunas consideraciones sobre algunos datos que aparecen en la muestra de habla recogida:

- La articulación del fonema/n/ representó un problema cuando este aparecía en coda de sílaba o al final de la palabra. 
- El sonido / $\mathrm{g} /$ parece haber sido adquirido por el niño. Su omisión en la palabra chocolate se debió posiblemente a la extensión de la misma.

- El fonema /d/ todavía estaba en proceso de adquisición cuando se realizó el estudio de caso, puesto que lo articuló correctamente solo en algunas ocasiones.

- El fonema /g/ todavía no estaba totalmente adquirido: por ejemplo, el niño no articuló siempre de forma correcta la palabra gota.

- No se obtuvieron muchos datos sobre el fonema $/ K /$, pero parecía adquirido.

- Lope no lograba articular el sonido / $\theta /$ y solía sustituirlo por /s/, pero este fenómeno es normal considerada su edad, como se puede apreciar en el Cuadro 4 del A-RE-HA (Aguilar Mediavilla y Serra Raventós 2007b: 28).

- $\quad$ El fonema /s/ parece haber sido adquirido, aunque su articulación representó un problema cuando este aparecía en grupos consonánticos o en coda de sílaba delante de otro sonido consonántico (p.ej. plastilina articulado [latilina]).

- El sonido /r/ representó el problema mayor para Lope: no lo articulaba en la mayoría de los casos, independientemente de la posición en la que apareciera; sin embargo, en algunos casos, se produjo una lateralización de la vibrante simple y el sonido se sustituyó por /1/.

Cabe hacer unas últimas consideraciones sobre la posible influencia del habla de los padres en la fonología del niño. De hecho, como ellos mismos especificaron en los documentos elaborados previamente a las pruebas, ambos proceden del Sur de América, la madre es de Ecuador y el padre de Chile, y es posible que esto haya ejercido una influencia importante en la articulación de algunos fonemas por parte del hijo. Un primer ejemplo de esta posible influencia está relacionado con la articulación del fonema /l/ por / r/ en algunos casos. Este fenómeno se conoce como lambdacismo y, según Álvarez Menéndez (2005), se registra tanto en la costa de Ecuador como en el centro de Chile. Por lo tanto, es posible que esta manifestación fonética esté presente en el habla de los padres y haya influido en la pronunciación del hijo. Otro factor importante que hay que evaluar es el posible seseo de los padres. De hecho, este fenómeno lingüístico es muy común en el sur de América y, si los padres pronuncian /s/ en lugar de $/ \theta /$, esto puede tener una influencia relevante en la fonética y la fonología del niño, que durante la investigación demostró tener problemas en la articulación de $/ \theta /$. Sin embargo, no se puede afirmar con seguridad si este es un ejemplo de seseo o si se debe a la falta de adquisición del fonema $/ \theta /$.

Si se compara la muestra fonológica del niño con el Cuadro 4 del A-RE-HA: "Incidencia de los procesos fonológicos de simplificación en castellano" (Aguilar Mediavilla y Serra 
Raventós 2007b: 28), se puede notar que algunos de los fenómenos que se han destacado durante el trabajo de investigación son característicos del habla de los niños castellanohablantes a los 5 años de edad. En primer lugar, como se muestra en el cuadro, en el 30-39\% de los casos, a los 5 años se puede hallar una reducción de los grupos consonánticos (p. ej. reducción del grupo /gr/ en tigre, /pl/ en plastilina y /br/ en liebre). Otros fenómenos presentes en el habla de Lope típicos de su edad, pero menos frecuentes, son la ausencia de /r/ y la omisión de consonante final de palabra, que se hallan en general en el 20-29\% de los casos. Se pudo notar también, en el habla del niño, la sustitución del fonema $/ \theta /$ por /s/, la lateralización de fonemas (en el presente caso, la lateralización de /r/ en /l/), la pronunciación de /d/ como líquida (p.ej. boda articulado /bola/) y la ausencia de / $/$, este último uno de los problemas mayores del niño; estos fenómenos son poco frecuentes, puesto que se encuentran en el 10-19\% de los casos, de acuerdo con Aguilar Mediavilla y Serra Raventós (2007b), pero siguen siendo parte del habla de esa edad. Dos últimos procesos que se observaron en el estudio de caso y que normalmente se hallan en menos del 10\% de los niños son la omisión de consonante inicial, como en chocolate, y la metátesis (en lugar de decir tambor, el niño articuló /tablo/, lateralizando el sonido / $/$ / en /l/ y desplazándolo).

En el nivel morfosintáctico, como se pudo destacar a través de la observación directa y de la prueba de morfología, el niño no dominaba ni la flexión nominal ni la sintaxis. En general, sus emisiones se limitaban a un único sustantivo o bien empleaba estructuras estereotipadas que había aprendido de las profesoras, sin construir frases sintácticamente desarrolladas. Solamente se recogió un caso en el que emitió una construcción formada por dos verbos en infinitivo: "quelé ecota" (querer recortar), con el significado de "quiero recortar". Por otra parte, no usaba los morfemas de plural en general, pero reconocía la presencia de la pluralidad. Durante la prueba de morfología, a menudo decía, por ejemplo: "reloj - os reloj" (articulando /os/ para indicar dos), demostrando así ser consciente de la presencia de más de un elemento en el recuadro, pero sin lograr formar gramaticalmente el plural. En cambio, palabras como botas y guantes, que se emplean generalmente en plural en el habla cotidiana, las dijo únicamente en plural y no logró formar el singular (emisiones lexicalizadas).

En el lenguaje del niño se notaron repeticiones frecuentes de sustantivos, verbos, breves oraciones que las profesoras le decían o que estaban diciendo a otros y que él escuchaba; por ejemplo, cuando se le preguntaba “¿qué es esto?” y no lo sabía, repetía el enunciado.

En relación con la comunicación e interacción con los demás, Lope consiguió también una muy buena competencia comunicativa: saludaba a los compañeros y a las profesoras, 
cuando no quería trabajar decía "no", si no entendía algo decía “¿eso?” o “qué es eso?", estructura aprendida por imitación de las profesoras, para que se lo explicaran.

Por último, hay que comentar que alcanzó también buenas capacidades lectoras y, a la hora de leer, articulaba las palabras de forma más precisa y correcta que cuando hablaba normalmente; por ejemplo, articulaba correctamente la vibrante doble / $r$ en palabras como zorro y los grupos consonánticos de distintas palabras, como en metro.

\subsection{Discusión}

Como última etapa del estudio de este caso, se comparan los datos recogidos durante la investigación con la información general de la que se dispone sobre el TEA que se ha comentado anteriormente en el Marco Teórico.

En primer lugar, en relación con los síntomas del TEA y su manifestación, Roccella (2008) comenta que estos suelen aparecer precozmente y la alteración de las habilidades lingüísticas se manifiesta ya en edades tempranas. Los resultados del estudio de caso destacan que, por lo menos en el contexto lingüístico, los síntomas aparecieron de forma temprana: de hecho, en sus primeros años de vida Lope presentaba un lenguaje limitado y pasó por una fase de estancamiento lingüístico que empezó a los 8/9 meses y duró hasta los 3 años. El mismo Roccella (2008) explica que otro síntoma típico del autismo es la presencia de estereotipias. Durante la investigación, se pudo apreciar que el niño manifestaba varios ejemplos de estereotipias, como cubrirse los oídos al escuchar ruidos fuertes y frotarse los ojos.

Otro fenómeno importante que suele aparecer en niños autistas es el uso de conductas agresivas y de autolesión como instrumento de comunicación. Con respecto a este tema, el National Research Council (2001) señala que este tipo de comportamientos puede manifestarse no solo para sustituir los medios de comunicación comúnmente ausentes en los pacientes con TEA, sino también para llamar la atención de un interlocutor o como forma de protesta. En relación al presente estudio de caso, se pudo apreciar que este tipo de conducta se manifestó, puesto que los padres apuntaron que en el pasado el niño solía dar cabezazos en el suelo o en la pared por la frustración cuando ellos no le entendían.

Sin embargo, la información sobre el uso de gestos recogida durante la investigación contrasta con la idea afirmada por el National Research Council (2001), según la que los pacientes con TEA no suelen emplear gestos convencionales con fines comunicativos. De hecho, gracias al historial clínico, se pudo desprender que Lope podía emplear gestos para indicar y pedir lo 
que quería; este es un logro importante, ya que esta capacidad está conectada al desarrollo de la atención conjunta y esta suele estar comprometida en los pacientes con TEA.

Un elemento importante que se especifica en el DSM-V (Biondi y American Psychiatric Association 2014) es la adherencia a rutinas estrictas por parte de los pacientes con TEA; estas personas suelen seguir una rutina inflexible, tanto en los contextos cotidianos de la vida como en el lenguaje. La presencia de este síntoma se detectó también en el estudio de caso considerado; de hecho, los niños con TEA en el colegio seguían una rutina diaria bastante rígida y cualquier cambio afectaba profundamente al estado anímico de estos alumnos. En el caso de Lope, cuando una docente estaba ausente y fue sustituida por otra, el niño se demostró irritable todo el día y no quiso desarrollar algunas de las actividades que se le proponían.

En el nivel social, la bibliografía analizada anteriormente señala que en los trastornos del espectro autista se suelen detectar varias anomalías. Roccella (2008) afirma que uno de los síntomas principales del autismo es el aislamiento social; este aparece en edad temprana y compromete la normal interacción social, por consiguiente, la persona con autismo suele evitar el contacto físico y no emplea generalmente la comunicación no verbal. El DSM-V (Biondi y American Psychiatric Association 2014) añade que esta anomalía tiene consecuencias clínicamente significativas sobre la vida cotidiana del paciente, puesto que este tiene problemas en el normal desarrollo de actividades sociales y laborales. Sin embargo, durante la investigación se recogieron datos que no coinciden con estos conocimientos generales. De hecho, Lope se demostró amigable con sus compañeros, sobre todo en el aula de referencia y durante el recreo en el patio y, a menudo, abrazaba espontáneamente a otros niños o les daba besos en las mejillas. Además, el alumno demostró que sabía interactuar con las personas que estaban a su alrededor, ya que seguía órdenes e instrucciones, si quería algo, lo identificaba y lo pedía y durante el recreo jugaba con los compañeros de forma cooperativa. Asimismo, en el historial clínico, los padres señalaron que su hijo adquirió algunas herramientas de comunicación no verbal; de hecho, podía comunicarse a través de algunos gestos y expresiones faciales, aunque limitados, y sabía comprender los estados de ánimo de las personas que estaban a su alrededor, una habilidad importante que en los sujetos autistas no suele desarrollarse de forma normal.

En el nivel lingüístico, en el presente estudio de caso se pudieron recoger datos interesantes. En primer lugar, hay que recordar que Noens y Vanberckelaer-Onnes (2004) señalaron que el habla de niños con TEA suele presentar algunos neologismos debido a su percepción parcial del mundo. Asimismo, Wilkinson (1998) afirma que entre los varios 
fenómenos que se pueden encontrar en el lenguaje de los pacientes con TEA está la tendencia a hacer preguntas persistentes. Sin embargo, en el caso de Lope, estas dos manifestaciones lingüísticas no estaban presentes. De hecho, los padres afirmaron que el niño no empleaba palabras inventadas o una jerga propia para comunicarse; asimismo, durante la investigación, no se observó que el niño formulara preguntas de forma persistente.

Sin embargo, la observación del alumno permitió detectar la presencia de muchos síntomas lingüísticos del autismo, como el empleo de numerosas ecolalias, tanto inmediatas como diferidas. Como explica Prizant (1983), las ecolalias consisten en la repetición de actos de habla realizados por otras personas y pueden ser inmediatas, diferidas o matizadas. García de la Torre (2002) añade que este fenómeno es normal en el habla de todos los niños hasta los tres años porque representa una etapa del desarrollo lingüístico, sin embargo, en el paciente autista suele estar presente hasta edades más avanzadas. En el estudio de caso de Lope, se notó que las ecolalias solían ser muy frecuentes en sus actos lingüísticos y desarrollaban un papel importante, ya que este utilizaba muchas expresiones aprendidas a partir del habla de las profesoras para expresarse y comunicarse con los demás. Por ejemplo, cuando no reconocía un objeto, empleaba la estructura “¿qué es eso?” que aprendió a partir del habla de las docentes, quienes la utilizan a menudo en las actividades que prevén el reconocimiento de objetos para estimular a los alumnos. Estas observaciones apoyan la hipótesis según la cual Lope adquirió el lenguaje de una forma más gestáltica que analítica, adoptando, por lo tanto, el modelo típico de adquisición del lenguaje en sujetos con TEA según Prizant (1983).

\section{Conclusiones}

Teniendo en cuenta todo lo comentado a lo largo del trabajo y las investigaciones llevadas a cabo con el estudio de caso, se puede afirmar que se han alcanzado los objetivos del presente trabajo.

En primer lugar, se quería analizar qué es el autismo y qué síntomas se presentan normalmente en esta patología. Gracias al análisis de la literatura disponible sobre el trastorno, se concluye que el trastorno del espectro autista es un desorden neuropsiquiátrico y conductual que tiene distintas manifestaciones y afecta a varias áreas del desarrollo del paciente. Algunos de los síntomas de esta afección son la alteración de la comunicación y de la interacción social, así como la presencia de estereotipias. Fijando la atención en el nivel lingüístico, se aprecia que el lenguaje autista, en general, es muy heterogéneo y se caracteriza por la presencia de varios fenómenos, como las ecolalias y la inversión pronominal. Asimismo, los sujetos con TEA, a la hora de comunicarse, adhieren a una rutina lingüística y social muy 
estricta. Por la evidente complejidad de la situación lingüística de estos pacientes, es importante llevar a cabo una detallada evaluación de esta competencia para elaborar un perfil individual de cada paciente.

Posteriormente, se quería analizar la competencia lingüística de un estudio de caso concreto para averiguar qué comportamientos típicos se podían detectar en el mismo y para demostrar que cada caso de autismo es único y particular. Considerando los resultados de la investigación, se puede afirmar que Lope alcanzó un buen nivel de desarrollo de la competencia lingüística. Se pudieron observar en el habla del alumno varios fenómenos que se asocian normalmente al autismo, como el uso de ecolalias, la adherencia a rutinas muy estrictas y la presencia de comportamientos estereotipados. Sin embargo, se notaron en el niño buenas capacidades comunicativas y sociales, siendo esta una característica que contrasta con las conductas que generalmente se asocian al TEA.

Estos resultados sostienen la idea según la que cada caso de autismo es único, puesto que presenta distintas manifestaciones y en distinta gradación de los comportamientos señalados en la literatura científica. A pesar de que existan pautas generales para definir y diagnosticar los trastornos del espectro autista, no hay criterios absolutos que puedan asociarse a los mismos. Por lo tanto, es importante evaluar cada caso en detalle para trazar un perfil médico personalizado y específico y para que se pueda, a partir del mismo, realizar un plan de intervención que atienda a las necesidades y a los problemas del sujeto. Solo de esta forma se pueden alcanzar resultados satisfactorios y se puede permitir al paciente que tenga la mejor calidad de vida que pueda alcanzar.

\section{Referencias bibliográficas}

Aguilar Mediavilla, E. M. y M. Serra Raventós (2007): A-RE-PA. Anàlisi del retard de la parla. Protocols per a l'anàlisi de la fonètica i la fonologia infantil, Barcelona: Publicacions i edicions de la Universitat de Barcelona. Traducción al castellano:A-RE-HA: Análisis del retraso del habla. Protocolos para el análisis de la fonética y la fonología infantil, pp. 15-32.

Álvarez Menéndez, A. I. (2005): Hablar en español: la cortesía verbal, la pronunciación estandar del español, las formas de expresión oral, Oviedo: Universidad de Oviedo.

Álvarez-Alcántara, E. (2007): “Trastornos del espectro autista”, Revista Mexicana de Pediatría, 74 (6), pp. 269-276.

Biondi, M. (a cargo de) y American Psychiatric Association (2014): Manuale diagnostico e statistico dei disturbi mentali. Quinta edizione. DSM-5, Milano: Raffaello Cortina Editore. 
Cacciari, C. (2011): Psicologia del linguaggio, Bologna: Il Mulino.

Cestero Mancera, A. M. (2016): "La comunicación no verbal: propuestas metodológicas para su estudio", Linred, XIII (2), pp. 1-36.

Codesido García, A. I. (2006): "Evaluación no-estandarizada de patologías del lenguaje en niños castellanohablantes: análisis lingüístico de algunas pruebas", Lingüística clínicay neuropsicología cognitiva. Actas del Primer Congreso Nacional de Lingüística Clínica. Vol. 2: Lingüística y evaluación del lenguaje, pp. 39-55.

Cornelio-Nieto, J. O. (2009): "Autismo infantil y neuronas en espejo", Revista de neurología, 48 (Supl. 2), pp. 27-29.

García de la Torre, M. P. (2002): “Trastornos de la comunicación en el autismo”, Revista galegoportuguesa de psicoloxía e educación: revista de estudios e investigación en psicología y educación, $8,409-417$.

Graffi, G. y S. Scalise (2013): Le lingue e il linguaggio. Introduzione alla linguistica, Bologna: Il Mulino.

Mele, A. (responsable del proyecto), Bacigalupi, M. et al. (2011 - actualizado en 2015): Linea Guida 21. Il trattamento dei disturbi dello spettro autistico nei bambini e negli adolescenti, Italia: Ministero della Salute.

National Research Council (2001): Educating Children with Autism, Committee on Educational Interventions for Children with Autism, Catherine Lord and James P. McGee, Washington DC: National Academy Press.

Noens, I. e I. Vanberckelaer-Onnes (2004): "Making sense in a fragmentary world. Communication in people with autism and learning disability", Autism, 8 (2), pp. 197218.

O'Grady, W. (2010): Cómo aprenden los niños el lenguaje, Madrid: Ediciones AKAL, trad. por A. Benítez Burraco.

Prizant, B. M. (1983): "Language acquisition and communicative behavior in autism: Toward an understanding of the 'whole' of it", Journal of Speech and hearing Disorders, 48, pp. 296307.

Puyuelo, M. S., J. A. Rondal y E. H. Wiig (2000): Evaluación del Lenguaje, Barcelona: Elsevier España. 
Roccella, M. (2008): Neuropsichiatria infantile, Padova: Piccin Nuova Libraria S.p.A.

Serra i Raventos, M. (1984): "Semiología de la comunicación de los autistas", Revista de Logopedia, Foniatria y Audiologia, 3 (3), pp. 131-141.

Tager-Flusberg, H. (2004): "Strategies for conducting research on language in autism", Journal of Autism and Developmental Disorders 34 (1), pp. 75-80.

Wilkinson, K. M. (1998): "Profiles of language and communication skills in autism", en Mental retardation and developmental disabilities research reviews, 4, pp. 73-79.

\section{Referencias digitales}

DLE (21 de marzo de 2020): Autismo, s.m., definición 2. https://dle.rae.es/autismo?m=form

DLE (12 de marzo de 2021): Ecolalia, s.f., definición 1. https://dle.rae.es/ecolalia?m=form

MedlinePlus, Biblioteca Nacional de Medicina de EE. UU. (29 de septiembre de 2019): Diagnóstico diferencial. https://medlineplus.gov/spanish/pruebas-de-laboratorio/diag $\underline{\text { nostico-diferencial/ }}$

Regier, D. A., Kuhl, E. A. y D. J. Kupfer (2013): The DSM-5 Classification and criteria changes. https://onlinelibrary.wiley.com/doi/full/10.1002/wps.20050 